\title{
REVIEW
}

\section{Impact of cigarette smoke exposure on host-bacterial pathogen interactions}

\author{
J. Garmendia*,\#,ף, P. Morey*,\# and J.A. Bengoechea*,\#,+
}

ABSTRACT: The human respiratory tract of individuals with normal lung function maintains a finetuned balance, being asymptomatically colonised by the normal microbiota in the upper airways and sterile in the lower tract. This equilibrium may be disrupted by the exposure to insults such as cigarette smoke. In the respiratory tract, the complex and noxious nature of inhaled cigarette smoke alters host-microorganism interaction dynamics at all anatomical levels, causing infections in many cases. Moreover, continuous exposure to cigarette smoke itself causes deleterious effects on the host that can trigger the development of chronic respiratory diseases, such as chronic obstructive pulmonary disease (COPD) and lung cancer. COPD is an irreversible airflow obstruction associated with emphysema, fibrosis, mucus hypersecretion and persistent colonisation of the lower airways by opportunistic pathogens. COPD patients keep a stable (without exacerbation) but progressively worsening condition and suffer periodic exacerbations caused, in most cases, by infections. Although smoking and smoking-associated diseases are associated with a high risk of infection, most therapies aim to reduce inflammatory parameters, but do not necessarily take into account the presence of persistent colonisers. The effect of cigarette smoke on host-pathogen interaction dynamics in the respiratory tract, together with current and novel therapies, is discussed.

KEYWORDS: Airway mucociliary clearance, chronic obstructive pulmonary disease, corticosteroids, infectious diseases, inflammation, tobacco smoking

\section{EFFECT OF CIGARETTE SMOKE EXPOSURE ON THE HUMAN RESPIRATORY TRACT}

General features of the human respiratory tract

The human upper respiratory tract is colonised from birth by the respiratory microbiota. Colonisers are commensal microorganisms and/or opportunistic pathogens [1]. Microorganisms encompassing the human respiratory microbiota are highly adapted to the host and examples of co-evolution have been described for several human restricted opportunistic pathogens, such as Neisseria meningitidis, Neisseria gonorrhoeae and Moraxella catarrhalis [2]. Conversely, the lower respiratory tract of individuals with normal lung function is sterile. Maintenance of lung sterility is physiologically relevant, given that the lung is the region where the gas exchange takes place. Physical, anatomical and mechanical barriers, including nasal hair, coughing and the mucociliary escalator, constitute a first line of defence, avoiding the entry of microorganisms to the lower tract. The mucociliary escalator is a layer of hydration above the lung tissue that, combined with mucus and the cilia present on the respiratory epithelium, is a trapping and removal system for foreign particles and invading pathogens [3].
Alveolar epithelium consists of type I and II pneumocytes. Type I pneumocytes have an anatomical function; by covering $95 \%$ of the alveolar surface, they generate a thin barrier between the alveolar space and the blood vessels. Type II pneumocytes, despite covering only $5 \%$ of the alveolar surface, are more abundant in number than type I pneumocytes [4]. Pneumocytes play crucial roles in lung defence: 1) maintenance of a low lung surface tension, stopping the surfaces for gas exchange from sticking together, by synthesis, secretion and reabsorption of pulmonary surfactant; 2) transport of water and sodium; 3) metabolism of xenobiotic compounds; 4) lung regeneration; 5) recognition of pathogen-associated molecular patterns (PAMPs) by pattern recognition receptors; 6) secretion of antimicrobial peptides; 7) secretion of cytokines and chemokines that orchestrate host inflammatory responses; and 8) generation of a barrier to pathogen entry by tight junction formation between epithelial cells [5-9]. Alveolar macrophages are lung-resident professional phagocytes that are responsible for eliminating microorganisms by phagocytosis and phagolysosomal processing. Alveolar macrophages also secrete inflammatory mediators

\section{AFFILIATIONS}

*Programa de Infección e Inmunidad, Fundación Caubet-CIMERA and

${ }^{*}$ Centro de Investigación Biomédica en Red de Enfermedades Respiratorias (CIBERES), Bunyola, "Instituto de Agrobiotecnología, CSIC-Universidad Pública de Navarra-Gobierno de Navarra, Mutilva, and

${ }^{+}$Consejo Superior de Investigaciones Científicas (CSIC), Madrid, Spain.

\section{CORRESPONDENCE}

J. Garmendia

Instituto de Agrobiotecnología CSIC-Universidad Pública de Navarra-Gobierno de Navarra 31192 Mutilva

Navarra

Spain

E-mail: juncal.garmendia@

unavarra.es

Received:

April 082011

Accepted after revision: June 282011 First published online: July 072011 
directing, when necessary, neutrophil recruitment from the bloodstream to the alveolar space [10]. Moreover, airway cells produce a repertoire of soluble molecules that are essential players in microbial clearance of the lower tract. These molecules, which are present in the aqueous fluid on the surface of the respiratory tract, include the complement system, antimicrobial peptides, lysozyme, lactoferrin, the secretory leukoprotease inhibitor (SLPI), surfactant protein (SP)-A and SP-D [11].

The fine equilibrium orchestrated to guarantee alveolar sterility is altered upon continuous host exposure to noxious particles and gases present in the environment. In this review, we will focus on the deleterious effect of continuous exposure to tobacco smoking and the impact of such a noxious agent in the respiratory microbiota.

\section{Cigarettes and tobacco smoke: features and components}

A cigarette consists of a blend of tobaccos surrounded by a paper with a defined specification. Most cigarettes are filter tipped and tip ventilated. Tip ventilation means that mainstream smoke is diluted with a defined amount of air during a puff. The tobacco blend, the cigarette paper, the type and efficiency of the filter, and the degree of tip ventilation determine the chemical composition of cigarette smoke. When cigarettes are smoked, a complex mixture is inhaled into the respiratory system. During the sequence from lighting a cigarette to inhaling a puff of smoke, various overlapping chemical, physical and physiological phenomena occur, i.e. burning, pyrolysis, pyrosynthesis, distillation, sublimation and condensation processes [12]. Tobacco smoke is an aerosol consisting of solids and liquid droplets (the particulate ("tar") phase) in a gaseous phase. Approximately 4,700 different substances have been identified in fresh tobacco smoke. These include neutral gases, carbon oxides, nitrogen oxides, amides, imides, lactames, carboxylic acids, lactones, esters, aldehydes, ketones, alcohols, phenols, amines, volatiles $N$-nitrosamines, $N$-heterocycles, hydrocarbons, nitriles, anhydrides, carbohydrates, ethers, nitro-compounds, metals and short-/long-living radicals. The quantities of the components in the mainstream smoke of a single cigarette range from milligramme (water, carbon monoxide, carbon dioxide and nicotine) to picogramme levels (heterocyclic amines and heavy metals) [12]. Inhaled particulate matter is deposited in the respiratory tract depending on the particle size, with larger particles deposited in the upper and larger airways, and smaller particles penetrating deep into the alveolar spaces. Ineffective clearance of this particulate matter causes particle retention in lung tissues, resulting in a chronic, low-grade inflammation that may be important in the progression of chronic lung diseases associated with long-term smoking [13]. In addition to chemicals, the presence of microorganisms has been documented in cigarettes. All tobacco is cured, during which time there is a rapid growth of diverse bacteria and fungi, and accumulation of microbial toxins. Mesophilic bacteria have been found in both fresh and cured tobacco leaves. A range of additional bacteria and fungi have been found in minor amounts; moreover, storing cigarettes at high humidity results in elevated levels of fungi in the cigarette tobacco, leading to increased ergosterol concentrations in the smoke [14]. In addition, the bacterial metagenome of a cigarette-based study revealed 15 different classes of bacteria and a broad range of potential pathogens (Acinetobacter, Bacillus, Burkholderia, Clostridium, Klebsiella, Pseudomonas aeruginosa,
Serratia, Campylobacter, Enterococcus, Proteus and Staphylococcus) $[15,16]$. The risk of infection by potential pathogens from inhaling the mainstream smoke is currently unknown.

\section{Pathologies associated with tobacco smoking: an overview}

Smoking tobacco causes up to $90 \%$ of all lung cancers, and is a significant risk factor for stroke and heart attacks. Smoking is also recognised as a risk factor for a variety of respiratory tract and systemic infections in children and adults, including the common cold, influenza, pneumonia and tuberculosis [17]. Importantly, smoking is the leading risk factor for chronic obstructive pulmonary disease (COPD). COPD is characterised by a slowly progressive and irreversible airflow obstruction, and loss of lung tissue leading to emphysema and remodelling of tissue (fibrosis), both of which contribute to further lung function decline, reduced quality of life and high mortality $[3,18]$. Changes in the immune system, triggered by noxious particles and gases present in the tobacco smoke, lead to an inflammatory cellular infiltrate and to a pronounced and chronic lung inflammation. This, in turn, leads to other pathological changes, including chronic obstructive bronchitis with fibrosis and obstruction of small airways, emphysema with enlargement of airspaces and destruction of lung parenchyma, loss of lung elasticity, and closure of small airways $[19,20]$. Tobacco smoke also leads to lung infections by pathogenic bacteria and viruses, which are key triggers of the acute worsening of COPD that is called exacerbation [21]. Exacerbations are an additional major factor in the morbidity and mortality caused by COPD, and the major source of healthcare costs associated with the disease [22-24].

\section{Molecular and cellular mechanisms associated with COPD progression}

The effect of cigarette smoke on airway immunity has been extensively characterised in COPD and is summarised in figure 1 $[19,25]$. COPD progression is associated with the accumulation of inflammatory mucous exudates in the lumen, and infiltration of the wall by innate and adaptive inflammatory immune cells; these changes are coupled to a repair and remodelling process that ultimately thickens the airways walls [26]. An additional consequence of long-term smoking is the persistent colonisation of the lower respiratory tract by opportunistic pathogens, which often has an amplification effect on and contributes to the progression of the disease [27, 28].

Cigarette smoke has deleterious effects on the mucociliary system by promoting a decrease of the ciliary beating frequency, denudation of the ciliary epithelium, an increase in the number of goblet cells, submucosal gland hypertrophy and squamous cell metaplasia [29]. Cigarette smoke also damages the epithelial junctions, due to a significant downregulation of genes involved in the formation of tight junctions, such as occludin, ZO-1 and claudin-1, which leads to a decrease of transepithelial resistance, which is correlated to an increase in epithelial permeability [30, 31].

Cigarette smoke activates the respiratory epithelium, causing production of inflammatory mediators (tumour necrosis factor (TNF)- $\alpha$, interleukin (IL)-1 $\beta$, granulocyte-macrophage colonystimulating factor, IL-8 and leukotriene (LT) $\mathrm{B}_{4}$ ), which are responsible for activating and/or recruiting alveolar macrophages and neutrophils. Several studies have shown that there is an increase in the total number of neutrophils, macrophages 


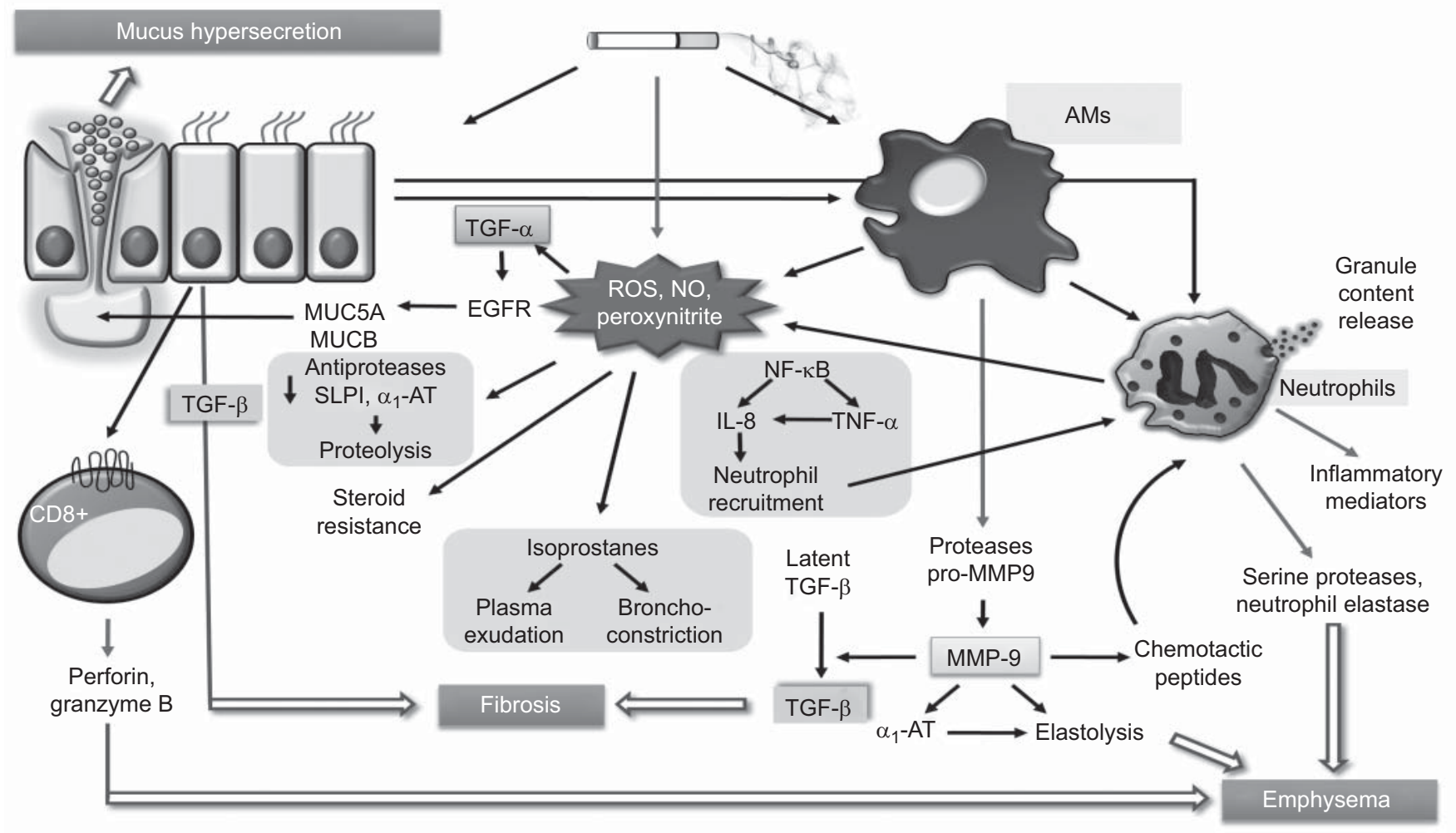

Lower airway colonisation by opportunistic pathogens: amplification effect

FIGURE 1. Molecular mechanisms involved in chronic obstructive pulmonary disease (COPD) progression. Three major host alterations characteristic of COPD progression, fibrosis, emphysema and mucus hypersecretion, are shown. A fourth characteristic of COPD progression, lower airway colonisation by opportunistic pathogens, is stated (bottom). Microbial persistency is relevant because it greatly contributes to deleterious amplification of COPD features. The main host cells involved in COPD patient airways, epithelial cells, alveolar macrophages (AMs), neutrophils and CD8+ lymphocytes, are shown. Cigarette smoke activates epithelial cells to produce inflammatory mediators, activating and/or recruiting AMs and neutrophils. Epithelial cells also secrete the local fibrosis inducer transforming growth factor (TGF)- $\beta$. Chemokines produced by epithelial cells and AMs activate CD8+ lymphocytes, which release the emphysema mediators perforin and granzyme. AMs secrete neutrophil chemoattractants and release proteases. Matrix metalloproteinase (MMP)- 9 activates the fibrosis inducer TGF- $\beta$ and causes elastolysis, either directly or by $\alpha_{1}$-antitrypsin (AT) inactivation. Proteases produced by AMs and neutrophils promote emphysema. Together with proteases, neutrophils secrete inflammatory mediators and granule contents. Neutrophil chemoattractants are produced directly by AMs and epithelial cells, and by enzymatic activity of the AM protease MMP-9. COPD patient airways display oxidative stress. Cigarette smoke itself contains high levels of reactive oxygen species (ROS), and both AMs and neutrophils increase their respiratory burst in response to cigarette smoke. High concentrations of ROS and reactive nitrogen species have multiple consequences: 1) decreased antiprotease defences and proteolysis; 2) activation of nuclear factor (NF)-KB and neutrophil recruitment; 3) steroid resistance; 4) increased isoprostanes production; and 5) mucus hypersecretion. SLPI: secretory leukoprotease inhibitor; IL: interleukin; TNF: tumour necrosis factor; EGFR: epidermal growth factor receptor; NO: nitric oxide; MUC: mucin.

and T-lymphocytes in lung parenchyma and peripheral and central airways of COPD patients [20,32]. Epithelial cells in the small airways also secrete transforming growth factor (TGF)- $\beta$, which induces local fibrosis [19]. It is well known that cigarette smoke induces epithelial cell death, which also amplifies the ongoing inflammatory response [19]. Regarding the effect of cigarette smoke on the production of antimicrobial molecules by airway epithelial cells, the expression of the antimicrobial peptide human $\beta$-defensin (hBD)-2 in brushed bronchial epithelial cells from COPD patients has been found to be lower than in tissues from healthy subjects [33]; in addition, significantly decreased levels of SP-A and SP-D have been observed in smokers compared with nonsmokers [34]. Alveolar macrophages activated by cigarette smoke secrete a repertoire of inflammatory mediators, some of which (IL-8, growth-related oncogene $\alpha, \mathrm{LTB}_{4}$ and monocyte chemoattractant protein-1) are neutrophil chemoattractants [19]. Alveolar macrophages show an increase in the respiratory burst and release elastolytic enzymes, including matrix metalloproteinases (MMPs) and cathepsins K, L and S. These enzymes, MMP-9 in particular, contribute to alveolar emphysema by enhancing the effects of elastase released by neutrophils [19]. Even though the inflammatory response of smokers is clearly different to that of nonsmokers, the effect of cigarette smoke on the expression of Toll-like receptor (TLR)2, TLR4 and CD14 on alveolar macrophages and monocytes in response to their ligands is currently unclear [35, 36]. Neutrophils, recruited due to the elevated levels of chemoattractants released by epithelial cells and macrophages, show an increase in the respiratory burst and secrete serine proteases (neutrophil elastase, cathepsin G, proteinase 3, MMP-8 and MMP-9) due to degranulation. The tripeptide proline-glycine-proline (PGP) (and the $\mathrm{N}$-acetylated form of PGP) is a selective neutrophil chemoattractant generated from extracellular matrix proteins 
through enzymatic reactions catalysed by MMP-8 and MMP-9. LTA $_{4}$ hydrolase $\left(\mathrm{LTA}_{4} \mathrm{H}\right)$ produced by neutrophils and epithelial cells has a dual function. It generates $\mathrm{LTB}_{4}$ and it has aminopeptidase activity, thus inactivating PGP, which contributes to the resolution of the neutrophilic inflammation in acute lung infections once the pathogen is no longer present. Smoke inhibits $\mathrm{LTA}_{4} \mathrm{H}$ aminopeptidase activity and stabilises PGP through acetylation; in this way, neutrophil migration into the lung increases, leading to persistent inflammation [37]. Cigarette smoke exposure also results in a suppression of neutrophil caspase-3-like activity, which ultimately impairs its phagocytic activity [38]. Importantly, cigarette smoke exposure causes an impairment of both alveolar macrophage and neutrophil phagocytic activity [39-42].

Oxidative stress is an imbalance that occurs when reactive oxygen species (ROS) cannot be controlled by antioxidant defence mechanisms (enzymatic defence mechanisms: catalase, superoxide dismutase, glutathione peroxidase, etc.; nonenzymatic defence mechanisms: glutathione (GSH), ascorbate, urate, etc.) and results in harmful effects [19]. Oxidative stress plays a key role in the pathophysiology of smoking-associated diseases [43-45]. ROS from cigarette smoke itself (the gas phase is estimated to contain $>10^{15}$ free radicals [46]) and those produced by inflammatory cells (alveolar macrophage and neutrophil respiratory burst induced by cigarette smoke) result in inflammatory and destructive damaging effects [43]. These effects include: 1) an overall increase in protease activity leading to emphysema; 2) amplification of the inflammatory response due to ROS-induced activation of nuclear factor (NF)$\kappa \mathrm{B}$, resulting in increased secretion of IL- 8 and TNF- $\alpha$, and subsequent neutrophil recruitment; 3) steroid resistance (see later); 4) increased oxidation of arachidonic acid leading to the production of isoprostanes, which trigger bronchoconstriction and plasma exudation; 5 ) activation of TACE (TGF- $\alpha$-converting enzyme), which promotes the shedding of TGF- $\alpha$ and the activation of the epidermal growth factor receptor (EGFR), resulting in the increased expression of mucin (MUC5AC and $M U C B)$ genes and the differentiation of mucus-secreting cells [19]. Differentiation of goblet cells via EGFR activation and mucus secretion are also stimulated by IL-13 [47]. The excess production of mucus contributes to the occlusion of the small airways in COPD. Independently, ROS also activate c-Jun Nterminal kinases via Src, triggering MUC5AC expression in an EGFR-independent manner [48].

Cigarette smoke also has an effect on host adaptive immunity. Smoking has been shown to reduce serum levels of immunoglobulins (Igs) in humans $[49,50]$. Moreover, there is an increase in the total number of T-lymphocytes in lung parenchyma and peripheral and central airways of COPD patients, which is more prominent for CD8+ cells $[19,51]$. These patients show an increase in mature dendritic cells (DCs) in the peripheral airways, and DCs from smokers display an increased expression of CD80 and CD86 [52]; it is likely that material in the lungs of smokers is taken up by these cells and presented by DC major histocompatibility complex class I molecules to CD8+ lymphocytes. Once activated by antigen-bearing DCs, T-cells may access the lung parenchyma by means of their tissue-specific chemokine receptors [20]. Indeed, T-cells in peripheral airways of COPD patients show increased expression of CXC chemokine receptor $(\mathrm{CXCR}) 3$, particularly CD8+ cells. The ligands for
CXCR3 (CXC chemokine ligand (CXCL)9, CXCL10 and CXCL11) are expressed by bronchial epithelial cells, airway smooth muscle cells and alveolar macrophages, which would contribute to CD8+ cell accumulation $[19,53]$. CD8+ cytotoxic Tcell abundance in the lungs of COPD patients correlates with the degree of airflow obstruction and emphysema; CD8+ cells cause alveolar epithelial cell death through the release of perforin and granzyme A and B [20,54]. CD4+ T-cells are also found in large numbers in the airways and parenchyma of COPD patients, where they express STAT-4 (signal transducer and activator of transcription), interferon (IFN)- $\gamma$ and T-helper cell (Th) type 1 cytokines, contributing to transendothelial migration of inflammatory cells to the airways; this recruitment progresses as COPD worsens [20]. However, cigarette smoke suppresses Th1mediated immune response to Gram-negative bacterial infections by interfering with MyD88/IL-1 receptor-associated kinase signalling, thereby reducing lipopolysaccharide (LPS)-induced TLR4 expression; this may contribute to explaining the increased susceptibility to bacterial infections in COPD [55].

\section{EFFECT OF CIGARETTE SMOKE EXPOSURE ON BACTERIAL INFECTIONS}

Continuous exposure to cigarette smoke has been associated with changes in the composition of the nasopharyngeal microflora. In smokers, this contains larger proportions of opportunistic pathogens (Streptococcus pneumoniae, Haemophilus influenzae, M. catarrhalis and Streptococcus pyogenes) than that of never-smokers, which mainly contains $\alpha$-haemolytic streptococci, Peptostreptococcus spp. and Prevotella spp. [56]. Interestingly, smoking cessation is associated with a reversion to the microflora found in never-smokers, thereby suggesting that cigarette smoke does indeed favour colonisation by pathogens [57]. Supporting this notion, cigarette smoke enhances bacterial attachment to epithelial cells and promotes changes in virulence by modifying bacterial gene expression [58-60].

Cigarette smoke affects the upper airways. Tobacco smoke is a risk factor for periodontitis [61-63], being a more severe disease in smokers than in never-smokers $[62,64]$. Tobacco smoke promotes colonisation of the subgingival space by opportunistic pathogens, such as Porphyromonas gingivalis, Campylobacter rectus, Prevotella intermedia, Tannerella forsythia, Treponema denticola and Fusobacterium nucleatum [63, 65-67]. Smoking cessation correlates with a decrease of periodontal pathogen prevalence $[65,68]$. $P$. gingivalis is the causative agent of chronic periodontitis; when bacteria are exposed to cigarette smoke, an increased expression of the bacterial fimbrial protein FimA has been observed, which could abrogate bacterially triggered inflammatory responses, and promote biofilm formation and bacterial adherence to the airway epithelium [58]. Cigarette smoke also promotes changes in the sinonasal microbiota, driving the formation of reversible, robust biofilms that may be involved in recalcitrant bacterial persistence in the nasal cavity [69]. Tobacco smoking is related to an increase in the occurrence and severity of acute infections by bacterial pathogens [61, 70]. Moreover, second-hand smoke causes a wide range of diseases in children. Parental smoking increases infant carriage of S. pneumoniae in general, and carriage of serotypes included in the conjugate seven-valent vaccine in particular [71]. Parental smoking also increases the risk of meningococcal meningitis [72, 73], otitis media [1] and lower respiratory tract infection in infants $<2$ yrs of age [74]. 


\section{The vicious circle hypothesis}

An additional consequence of cigarette smoke exposure is the persistent colonisation of the lower respiratory tract by opportunistic microbial pathogens. Such chronic microbial colonisation contributes to COPD progression by further amplifying the inflammatory processes previously described. The "vicious circle" hypothesis was proposed to explain how chronic bacterial colonisation of the lower airways in smokers can perpetuate inflammation and contribute to the progression of smoking-associated diseases (fig. 2) [28, 75]. Central to this hypothesis is the notion that once pathogens have gained a foothold in the lower respiratory tract due to smoking-triggered impairment of mucociliary clearance, they persist by further blocking mucociliary clearance [28, 75]. Cigarette smoke also upregulates mucus production, impairs epithelial elastic properties, downregulates the levels of IgA and affects the phagocytic activity of professional phagocytes [19, 41]. Together, these alterations facilitate bacterial colonisation of the lower respiratory tract, which is associated with an exacerbation of the inflammatory response due to the recognition of PAMPs. Both bacterial products and bacterially produced epithelial damage contribute to the impairment of host immunity, further allowing the access of microorganisms to the lower respiratory tract in an endless loop, ultimately translated into high chronic inflammation and persistent microbial colonisation of the lungs [75]. This endless loop is known as a vicious circle [28, 75]. Microorganisms frequently isolated from the lower respiratory tract of smokers and of persistently colonised patients are nontypeable $H$. influenzae (NTHi), M. catarrhalis, S. pneumoniae and P. aeruginosa. The most frequently isolated pathogen, and the one responsible for a significant percentage of exacerbation episodes in COPD, is NTHi $[76,77]$.

\section{Effect of smoking on NTHi, M. catarrhalis, S. pneumoniae and $P$. aeruginosa infections}

$H$. influenzae is a member of the human respiratory microflora located mainly in the oro- and nasopharynx. It colonises 40 $80 \%$ of healthy individuals, with a frequency of carriage that is higher in children than in adults $[1,78]$. Transmission occurs via aerosols or direct contact with mucosal surfaces. $H$. influenzae carriers are simultaneously colonised with multiple strains in continuous renewal, which are mainly nontypeable (noncapsulated) [79, 80]. H. influenzae is endowed with molecular strategies to adapt to the host, evade predation, and compete or coexist with other bacteria from the same or different species, such as Staphylococcus aureus and S. pneumoniae [81]. Simultaneous presence of $H$. influenzae and $S$. pneumoniae in the upper respiratory tract triggers a synergistic inflammation, resulting in neutrophil recruitment to the respiratory mucosa [82]. This neutrophil recruitment leads to a selective killing of complement-opsonised S. pneumoniae. Cocolonisation by $S$. pneumoniae and $H$. influenzae provides a stimulus ( $H$. influenzae peptidoglycan) to induce neutrophiland complement-mediated clearance of $S$. pneumoniae from the mucosal surface in a Nod1-dependent manner [83, 84]. $H$. influenzae co-colonisation seems to favour the selection of opsonophagocytosis-resistant S. pneumoniae capsule serotypes. Thus, competition with $H$. influenzae in the commensal state turns pneumococci into more virulent populations, which may account for further development of invasive disease [85]. Although cigarette smoke does not seem to alter NTHi viability [41], host cell exposure to this irritant reduces bacterial invasion of respiratory epithelial cells (unpublished data) and alveolar macrophage phagocytic ability [39-42]. Normally, alveolar macrophages efficiently phagocytose and

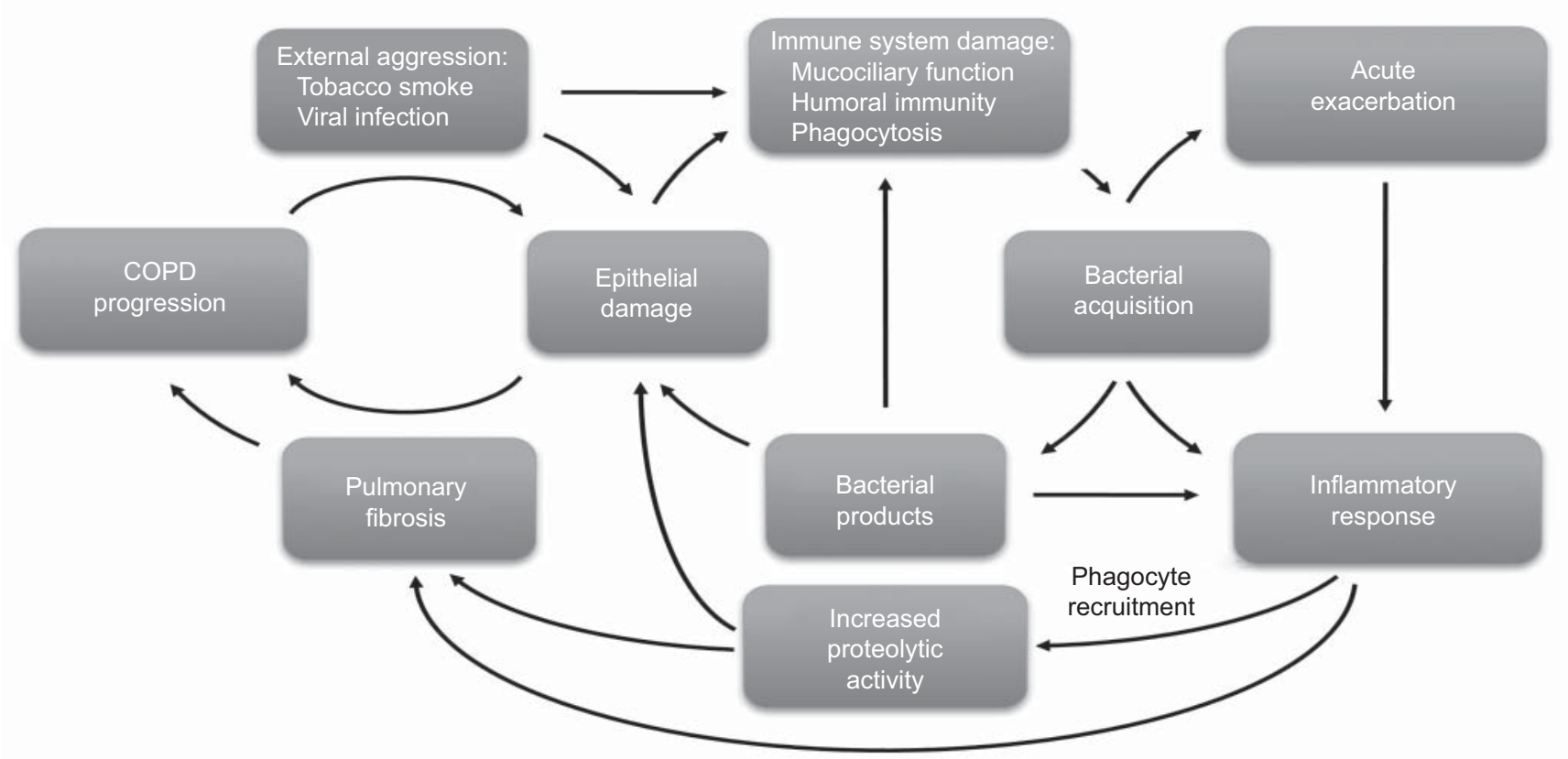

FIGURE 2. The vicious circle hypothesis of chronic obstructive pulmonary disease (COPD) progression. Cigarette smoke is an external insult that damages respiratory tract immunity, allowing lower respiratory tract colonisation by microorganisms. Such colonisation is a starting point for a cyclic sequence of events that progressively contribute to a high level of chronic inflammation, tissue damage and fibrosis, together with persistent bacterial infection of the lower airways. Together, these processes continuously contribute to the nonreversible progression of the chronic respiratory disease. 
degrade NTHi by phagolysosomal fusion. Cigarette smoke dramatically impairs bacterial ingestion, but not the ingestion of inert particles. Phosphoinositide 3-kinase (PI3K) signalling, including Akt phosphorylation, is required for NTHi phagocytosis by alveolar macrophages. Cell exposure to cigarette smoke diminishes phospho-Akt levels, which may account for the observed phagocytic deficiency; the same observations were made using immortalised macrophages and macrophages from bronchoalveolar lavage (BAL) from both smokers and COPD patients, compared with macrophages from neversmokers [41]. The levels of LPS-binding protein (LBP) and CD14 are higher in BAL from smokers and COPD patients than from never-smokers [86]. Furthermore, cigarette smoke induces the expression of LBP and CD14 in airway epithelial cells. Both proteins inhibit NTHi-dependent secretion of IL-8, and both NF- $\mathrm{KB}$ and p38 mitogen-activated protein kinase (MAPK) signalling pathways, but they increase NTHi entry into epithelial cells [86]. Given that NTHi can reside inside a late endosome-like compartment [87], LBP and CD14 may indeed contribute to NTHi colonisation by favouring bacterial location inside a subcellular niche. Regarding adaptative immune cells, the main lymphocyte subsets shown to proliferate in response to NTHi stimulation are CD8+ and natural killer cells [88]; NTHi-specific CD4+ T-cells had a memory phenotype with moderate-to-high CD27 and CC chemokine receptor 7 expression, and circulated at low frequency in the peripheral blood of both healthy individuals and COPD patients [89].

Community-acquired pneumonia (CAP) is a major cause of hospitalisation and has high mortality rates. S. pneumoniae is the most commonly isolated pathogen from CAP patients [90]. Smoking is a substantial risk factor for pneumococcal pneumonia, especially in patients with COPD [91, 92], and for invasive pneumococcal disease [93]. Smoke also seems to exacerbate the impairment in mucociliary clearance of S. pneumoniae induced by the ingestion of ethanol [94]. Cigarette smoke has been shown to prevent complement-mediated phagocytosis of $S$. pneumoniae by alveolar macrophages, while the ingestion of unopsonised bacteria or IgG-coated microspheres is not affected, thus impairing pulmonary bacterial clearance [95].

M. catarrhalis causes $\sim 10 \%$ of exacerbations in COPD and also colonises the lower airways of stable patients. Analysis of a collection of inflammatory parameters in sputum samples from a cohort of COPD patients before and after $M$. catarrhalis acquisition revealed a significant increase in IL-8, TNF- $\alpha$ and neutrophil elastase levels after infection [96]. An independent study detected M. catarrhalis-specific Th1 cells in BAL fluid of COPD-infected patients [97]. Moreover, cigarette smoke has been shown to decrease $M$. catarrhalis-induced hBD-2 antimicrobial peptide expression and prostaglandin $E_{2}$ induction, and increase the bacterial load on the bronchial epithelium of smokers [33].

$P$. aeruginosa is another pathogen that is frequently isolated from pneumonia patients. Exposure to cigarette smoke increases host inflammation and decreases the rate of $P$. aeruginosa clearance [98]. The mechanism for the increased susceptibility to $P$. aeruginosa infection may be related to the fact that cigarette smoke decreases the expression of the cystic fibrosis transmembrane conductance regulator (CFTR) gene
[99]. Epidemiological studies indicate that COPD patients are usually infected with one $P$. aeruginosa clone that remains in the lung for years, without evidence of interpatient transmission; during chronic infection, the pathogen evolves towards an increased mutation rate, increased antibiotic resistance and reduced production of proteases, different coexisting morphotypes, and with patterns of infection and evolution that resemble those observed in cystic fibrosis [100].

Smokers are also more likely to suffer from Legionnaire's disease [101] and tuberculosis [102]. Tobacco smoke leads to loss of weight and increased mortality by impairing the CD4+ Tlymphocyte response to Mycobacterium tuberculosis, which is a key factor for macrophage IFN- $\gamma$-dependent activation and subsequent killing of intracellular M. tuberculosis [103]. Finally, Mycoplasma pneumoniae is another common pathogen in COPD patients [104]. As a consequence of smoking, the lung tries to maintain the redox environment by maintaining high levels of GSH and GSH reductase (GSH adaptive response). M. pneumoniae infection interferes with this response to cigarette smoking, causing oxidative stress, which may contribute to the progression of chronic disease [105].

\section{IMPACT OF ANTI-INFLAMMATORY THERAPIES ON BACTERIAL RESPIRATORY INFECTIONS}

Given that inflammation is a main feature of smoking-associated diseases, the control of both chronic and acute inflammation associated with exacerbations is a main issue in the treatment of these patients. COPD treatments are generally palliative, such as oxygen therapy, bronchodilators, mucolytic agents and antibiotics. The use of anti-inflammatory agents is also a usual practice in these patients; an extensively used therapy is based in corticosteroids [106, 107]. Considering that the upper (and frequently the lower) airways of patients receiving anti-inflammatory therapy are likely to be colonised, the effect of corticoids on pathogen-host interaction and/or microbial clearance should be taken into account. Exogenous blockage of the host inflammatory response to an infection could be detrimental for the host. Indeed, although glucocorticoid (dexamethasone in particular) treatment of cultured cells upon infection by S. pneumoniae, $N$. meningitidis or Aspergillus fumigatus has been shown to be effective in terms of inflammation reduction [108, 109], adverse effects of steroid therapy on resistance to infection have been reported [110]. As an example, dexamethasone seems to impair $P$. aeruginosa clearance by suppressing inducible nitric oxide synthase (iNOS) expression and peroxynitrite production [111]. Independently, dexamethasone attenuates NTHi-induced NF- $\kappa \mathrm{B}$ activation, but also synergistically enhances NTHi-induced TLR2 expression via specific upregulation of MAPK phosphatase (MKP)-1 that, in turn, leads to dephosphorylation and inactivation of p38 MAPK. Glucocorticoid-mediated inhibition of NTHiinduced MUC5A expression also occurs via MKP-1-dependent inhibition of p38 MAPK [112-115].

Airway epithelium exposure to cigarette smoke does not modify NTHi adhesion to the host cell surface, independently of the presence of dexamethasone. In contrast, cigarette smokemediated impairment of alveolar macrophage ability to phagocyte NTHi is not restored when cells are simultaneously treated with dexamethasone [41]. Conversely, the glucocorticoid fluticasone propionate seems to reduce the invasion of airway epithelial cells by S. pneumoniae [116]. 
These observations, together with the fact that the use of inhaled corticoids in COPD increases the risk of hospitalisation for pneumonia [117], support the notion that corticosteroids may facilitate infections, despite their efficacy in reducing smokingassociated inflammation. In addition, there is evidence indicating that exposure to cigarette smoke may limit the efficiency of corticosteroids to attenuate the transcription of inflammatory genes by affecting the balance between histone acetyltransferases and histone deacetylases (HDACs) (fig. 3) [118].

Therefore, alternative treatments become compulsory. Although several novel possibilities are available and others are at different stages of clinical trials [107, 119-121], it should be noted that in most cases, there is no information on their impact on hostpathogen interaction. Furthermore, this important aspect is hardly considered as an outcome in the ongoing clinical trials. Antioxidants and inhibitors of inducible iNOS may be effective, through inhibition of the generation of peroxynitrite. The available antioxidants are vitamins $\mathrm{C}$ and $\mathrm{E}$, and $\mathrm{N}$-acetylcysteine; selective iNOS inhibitors and peroxynitrite scavengers are being developed [118]. The HDAC activator theophylline [122] and the therapeutic inhibition of PI3K [123] have been shown to be able to reverse the steroid resistance induced by cigarette smoke. Other therapies are: 1) long-acting bronchodilators (long-acting $\beta_{2}$-agonist salmeterol or long-acting anticholinergic tiotropium); 2) mediator antagonists (inhibitors of $\mathrm{LTB}_{4}$, IL-8, TNF- $\alpha$ or EGFR); 3) protease inhibitors (endogenous antiproteases, such as $\alpha_{1}$-antitrypsin, SLPI, elafin, cystatins or small molecule inhibitors); and 4) novel anti-inflammatory treatments (inhibitors of phosphodiesterase (PDE)4, p38 MAPK, NF- $\mathrm{BB}$ or PI3K, or resveratrol) $[119,121]$. Salmeterol has been shown to contribute to the protection of the airway epithelial barrier from $P$. aeruginosa [124]. The combination of salmeterol and fluticasone propionate has been shown to attenuate the inflammatory response of human airway epithelial cells infected with $S$. aureus [125]. Although salmeterol also seems to protect the respiratory epithelium against $H$. influenzae-induced damage [126], in vivo data show that inhalation of this bronchodilator may negatively influence the effective clearance of NTHi from the murine respiratory tract [127]. In contrast, resveratrol has been shown to ameliorate Serratia marcescens-induced acute pneumonia in rats [128], inhibit swarming and virulence factor expression in Proteus mirabilis [129], be a potential candidate against various Helicobacter pylori-related gastric pathogenic processes [130], and selectively inhibit N. gonorrhoeae and N. meningitidis [131]. Finally, the increase of eukaryotic cyclic AMP levels by adenylate cyclase activation could have a benefit in the treatment of NTHi infections by reducing bacterial invasion of epithelial cells (A. López-Gómez, Fundación Caubet-Cimera, Mallorca, Spain; personal communication). Similar observations have been made
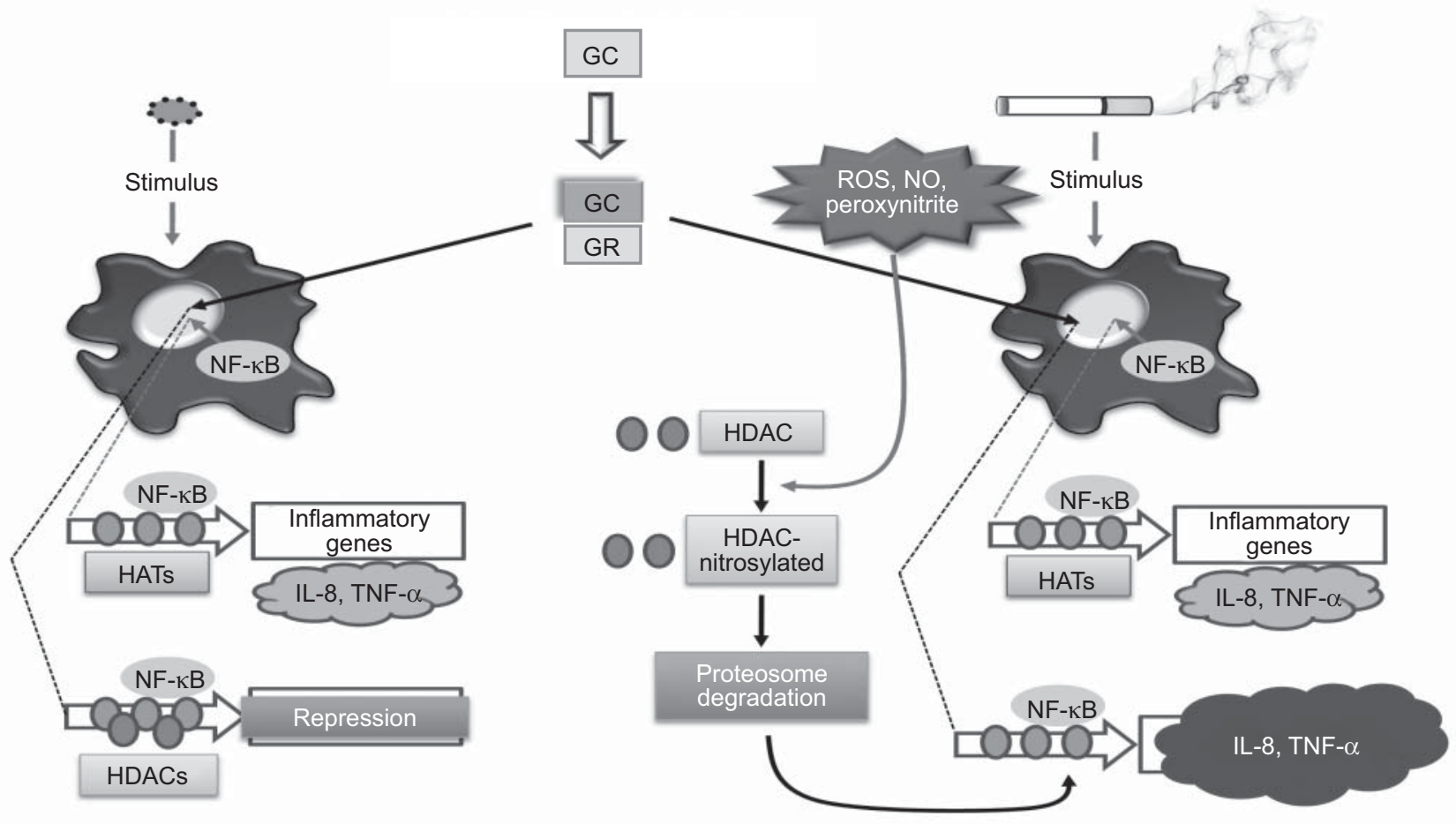

FIGURE 3. Cigarette smoke and host insensitivity to corticoids. Histone deacetylase (HDAC) reduction caused by cigarette smoke may account for an amplification of the inflammatory response (right) and insensitivity to the anti-inflammatory effect of corticoids (left). Cigarette smoke activates nuclear factor (NF)-kB in alveolar macrophages (right). Gene expression is activated by histone acetyltransferase (HAT)-mediated core histone acetylation; histone acetylation of inflammatory gene promoters activated by $\mathrm{NF}-\mathrm{kB}$ is increased in chronic obstructive pulmonary disease. The increase in acetylation is due to a reduction of HDACs. HDACs reverse histone acetylation and switch off gene transcription. HDACs are inactivated by oxidative and nitrosative stress. Oxidative and nitrosative stress lead to the formation of peroxynitrite, which nitrosylates HDAC, leading to its degradation, resulting in low HDAC levels and, subsequently, in an amplification of the inflammatory response. HDAC reduction by cigarette smoke-induced oxidative stress impairs the response to corticoids. Glucocorticoids (GCs) bind GC receptor (GR) and recruit HDAC to activated inflammatory genes; by reversing the acetylation of those genes, their transcription is switched off and the inflammation is reduced (left). IL: interleukin; TNF: tumour necrosis factor; ROS: reactive oxygen species; NO: nitric oxide. 
in urinary tract infections caused by uropathogenic Escherichia coli [132]. The PDE4 inhibitor rolipram has also shown to be effective in preventing $P$. aeruginosa-induced epithelial damage [133]. Also, PDE4 inhibition seems to impair host defense to Klebsiella pneumoniae infection in the pneumonia mouse model [134]. Together, these observations reinforce the notion that caution should be taken to extrapolate the findings obtained with one pathogen to infections caused by different microorganisms.

\section{FINAL REMARKS}

Alterations of the normal respiratory microflora caused by host exposure to external factors such as smoking have an undoubted impact on host health, and constitute a risk factor for chronic respiratory diseases and respiratory infections. Understanding the nature of host-pathogen dynamics is essential for the development of effective therapies, but the modulation of those dynamics by host exposure to environmental agents should also be considered. Moreover, therapies focused on the treatment of chronic respiratory diseases should also take into account the microbial component, if any, of the chronic disease, given that such therapies may influence, positively or negatively, pathogen clearance and, therefore, the progression of the chronic disease. In conclusion, we would like to put forward the notion that, before approval by competent authorities, any treatment likely to be taken by chronically colonised patients should be assessed in terms of its potential impact on host-pathogen dynamics, by testing a panel of relevant pathogens, and preferably including in vitro and in vivo approaches.

\section{SUPPORT STATEMENT}

Work in J. Garmendia's laboratory is supported by grants from Instituto de Salud Carlos III (ISCIII, Spain) (grants CP05-0027, PI06-1251 and PS09-0130) and Fundación Mutua Madrileña-2008 to J. Garmendia. Work in J.A. Bengoechea's laboratory is supported by a grant from Biomedicine Programme (SAF2009-07885, Ministerio de Ciencia e Innovación, Spain). CIBERES is an initiative of ISCIII.

\section{STATEMENT OF INTEREST}

None declared.

\section{REFERENCES}

1 García-Rodríguez JA, Fresnadillo Martínez MJ. Dynamics of nasopharyngeal colonization by potential respiratory pathogens. J Antimicrob Chemother 2002; 50: Suppl. S2, 59-73.

2 Voges M, Bachmann V, Kammerer R, et al. CEACAM1 recognition by bacterial pathogens is species-specific. BMC Microbiol 2010; 10: 117.

3 Taylor JD. COPD and the response of the lung to tobacco smoke exposure. Pulm Pharmacol Ther 2010; 23: 376-383.

4 Fereol S, Fodil R, Pelle G, et al. Cell mechanics of alveolar epithelial cells (AECs) and macrophages (AMs). Respir Physiol Neurobiol 2008; 163: 3-16.

5 Castranova V, Huffman LJ, Judy DJ, et al. Enhancement of nitric oxide production by pulmonary cells following silica exposure. Environ Health Perspect 1998; 106: Suppl. 5, 1165-1169.

6 Chaudhuri N, Sabroe I. Basic science of the innate immune system and the lung. Paediatr Respir Rev 2008; 9: 236-242.

7 Mason RJ. Biology of alveolar type II cells. Respirology 2006; 11: S12-S15.

8 Rubovitch V, Gershnabel S, Kalina M. Lung epithelial cells modulate the inflammatory response of alveolar macrophages. Inflammation 2007; 30: 236-243.
9 Zhang P, Summer WR, Bagby GJ, et al. Innate immunity and pulmonary host defense. Immunol Rev 2000; 173: 39-51.

10 Naito M. Macrophage differentiation and function in health and disease. Pathol Int 2008; 58: 143-155.

11 Bals R, Hiemstra PS. Innate immunity in the lung: how epithelial cells fight against respiratory pathogens. Eur Respir J 2004; 23: 327-333.

12 Borgerding $\mathrm{M}$, Klus $\mathrm{H}$. Analysis of complex mixtures - cigarette smoke. Exp Toxicol Pathol 2005; 57: 43-73.

13 Ling SH, van Eeden SF. Particulate matter air pollution exposure: role in the development and exacerbation of chronic obstructive pulmonary disease. Int J Chron Obstruct Pulmon Dis 2009; 4: 233-243.

14 Larsson L, Szponar B, Ridha B, et al. Identification of bacterial and fungal components in tobacco and tobacco smoke. Tob Induc Dis 2008; 4: 4.

15 Pauly JL, Smith LA, Rickert $\mathrm{MH}$, et al. Review: Is lung inflammation associated with microbes and microbial toxins in cigarette tobacco smoke? Immunol Res 2010; 46: 127-136.

16 Sapkota AR, Berger S, Vogel TM. Human pathogens abundant in the bacterial metagenome of cigarettes. Environ Health Perspect 2010; 118: 351-356.

17 Arcavi L, Benowitz NL. Cigarette smoking and infection. Arch Intern Med 2004; 164: 2206-2216.

18 MacNee W. Pathogenesis of chronic obstructive pulmonary disease. Proc Am Thorac Soc 2005; 2: 258-266.

19 Barnes PJ. Mediators of chronic obstructive pulmonary disease. Pharmacol Rev 2004; 56: 515-548.

20 Cosío MG, Saetta M, Agustí A. Immunologic aspects of chronic obstructive pulmonary disease. $N$ Engl J Med 2009; 360: 2445-2454.

21 Celli BR, Barnes PJ. Exacerbations of chronic obstructive pulmonary disease. Eur Respir J 2007; 29: 1224-1238.

22 Barnes PJ. Prevention of death in COPD. N Engl J Med 2007; 356: 2211.

23 Barnes PJ, Celli BR. Systemic manifestations and comorbidities of COPD. Eur Respir J 2009; 33: 1165-1185.

24 Hansel TT, Barnes PJ. New drugs for exacerbations of chronic obstructive pulmonary disease. Lancet 2009; 374: 744-755.

25 Barnes PJ. The cytokine network in chronic obstructive pulmonary disease. Am J Respir Cell Mol Biol 2009; 41: 631-638.

26 Hogg JC, Chu F, Utokaparch S, et al. The nature of small-airway obstruction in chronic obstructive pulmonary disease. $N$ Engl J Med 2004; 350: 2645-2653.

27 Mizgerd JP. Acute lower respiratory tract infection. N Engl J Med 2008; 358: 716-727.

28 Sethi S, Murphy TF. Bacterial infection in chronic obstructive pulmonary disease in 2000: a state-of-the-art review. Clin Microbiol Rev 2001; 14: 336-363.

29 Mehta H, Nazzal K, Sadikot RT. Cigarette smoking and innate immunity. Inflamm Res 2008; 57: 497-503.

30 Maunders H, Patwardhan S, Phillips J, et al. Human bronchial epithelial cell transcriptome: gene expression changes following acute exposure to whole cigarette smoke in vitro. Am J Physiol Lung Cell Mol Physiol 2007; 292: 1248-1256.

31 Olivera DS, Boggs SE, Beenhouwer C, et al. Cellular mechanisms of mainstream cigarette smoke-induced lung epithelial tight junction permeability changes in vitro. Inhal Toxicol 2007; 19: 13-22.

32 Sopori M. Effects of cigarette smoke on the immune system. Nat Rev Immunol 2002; 2: 372-377.

33 Zhang W, Case $\mathrm{S}$, Bowler RP, et al.Cigarette smoke modulates $\mathrm{PGE}_{2}$ and host defence against Moraxella catarrhalis infection in human airway epithelial cells. Respirology 2011; 16: 508-516.

34 Honda Y, Takahashi H, Kuroki Y, et al. Decreased contents of surfactant proteins A and D in BAL fluids of healthy smokers. Chest 1996; 109: 1006-1009. 
35 Droemann D, Goldmann T, Tiedje T, et al. Toll-like receptor 2 expression is decreased on alveolar macrophages in cigarette smokers and COPD patients. Respir Res 2005; 6: 68.

36 Regueiro V, Campos MA, Pons J, et al. The uptake of a Klebsiella pneumoniae capsule polysaccharide mutant triggers an inflammatory response by human airway epithelial cells. Microbiology 2006; 152: 555-566.

37 Snelgrove RJ, Jackson PL, Hardison MT, et al. A critical role for $\mathrm{LTA}_{4} \mathrm{H}$ in limiting chronic pulmonary neutrophilic inflammation. Science 2010; 330: 90-94.

38 Stringer KA, Tobias $\mathrm{M}, \mathrm{O}^{\prime} \mathrm{Neill} \mathrm{HC}$, et al. Cigarette smoke extract-induced suppression of caspase-3-like activity impairs human neutrophil phagocytosis. Am J Physiol Lung Cell Mol Physiol 2007; 292: L1572-L1579.

39 Berenson CS, Garlipp MA, Grove LJ, et al. Impaired phagocytosis of nontypeable Haemophilus influenzae by human alveolar macrophages in chronic obstructive pulmonary disease. J Infect Dis 2006; 194: 1375-1384.

40 Hodge S, Hodge G, Ahern J, et al. Smoking alters alveolar macrophage recognition and phagocytic ability: implications in chronic obstructive pulmonary disease. Am J Respir Cell Mol Biol 2007; 37: 748-755.

41 Martí-Lliteras P, Regueiro V, Morey P, et al. Nontypeable Haemophilus influenzae clearance by alveolar macrophages is impaired by exposure to cigarette smoke. Infect Immun 2009; 77: 4232-4242.

42 Taylor AE, Finney-Hayward TK, Quint JK, et al. Defective macrophage phagocytosis of bacteria in COPD. Eur Respir J 2010, 35: 1039-1047.

43 MacNee W. Oxidative stress and lung inflammation in airways disease. Eur J Pharmacol 2001; 429: 195-207.

44 MacNee W, Rahman I. Is oxidative stress central to the pathogenesis of chronic obstructive pulmonary disease? Trends Mol Med 2001; 7: 55-62.

45 MacNee W. Oxidants/antioxidants and chronic obstructive pulmonary disease: pathogenesis to therapy. Novartis Found Symp 2001; 234: 169-185.

46 Pryor WA, Stone K. Oxidants in cigarette smoke. Radicals, hydrogen peroxide, peroxynitrate, and peroxynitrite. Ann NY Acad Sci 1993; 686: 12-27.

47 Shim JJ, Dabbagh K, Ueki IF, et al. IL-13 induces mucin production by stimulating epidermal growth factor receptors and by activating neutrophils. Am J Physiol Lung Cell Mol Physiol 2001; 280: 134-140.

48 Gensch E, Gallup M, Sucher A, et al. Tobacco smoke control of mucin production in lung cells requires oxygen radicals AP-1 and JNK. J Biol Chem 2004; 279: 39085-39093.

49 Ferson M, Edwards A, Lind A, et al. Low natural killer-cell activity and immunoglobulin levels associated with smoking in human subjects. Int J Cancer 1979; 23: 603-609.

50 González-Quintela A, Alende R, Gude F, et al. Serum levels of immunoglobulins (IgG, IgA, IgM) in a general adult population and their relationship with alcohol consumption, smoking and common metabolic abnormalities. Clin Exp Immunol 2008; 151: $42-50$.

51 Saetta M, Baraldo S, Corbino L, et al. CD8+ve cells in the lungs of smokers with chronic obstructive pulmonary disease. Am J Respir Crit Care Med 1999; 160: 711-717.

52 Bratke K, Klug M, Bier A, et al. Function-associated surface molecules on airway dendritic cells in cigarette smokers. Am J Respir Cell Mol Biol 2008; 38: 655-660.

53 Saetta $\mathrm{M}$, Mariani $\mathrm{M}$, Panina-Bordignon $\mathrm{P}$, et al. Increased expression of the chemokine receptor $\mathrm{CXCR} 3$ and its ligand CXCL10 in peripheral airways of smokers with chronic obstructive pulmonary disease. Am J Respir Crit Care Med 2002; 165: 1404-1409.
54 Chrysofakis G, Tzanakis N, Kyriakoy D, et al. Perforin expression and cytotoxic activity of sputum CD8+ lymphocytes in patients with COPD. Chest 2004; 125: 71-76.

55 Knobloch J, Schild K, Jungck D, et al. The T-helper cell type 1 immune response to Gram-negative bacterial infections is impaired in COPD. Am J Respir Crit Care Med 2011; 183: 204-214

56 Brook I, Gober AE. Recovery of potential pathogens and interfering bacteria in the nasopharynx of otitis media-prone children and their smoking and nonsmoking parents. Arch Otolaryngol Head Neck Surg 2005; 131: 509-512.

57 Brook I, Gober AE. Effect of smoking cessation on the microbial flora. Arch Otolaryngol Head Neck Surg 2007; 133: 135-138.

58 Bagaitkar J, Demuth DR, Daep CA, et al. Tobacco upregulates $P$. gingivalis fimbrial proteins which induce TLR2 hyposensitivity. PLoS One 2010; 5: e9323.

59 Bagaitkar J, Williams LR, Renaud DE, et al. Tobacco-induced alterations to Porphyromonas gingivalis-host interactions. Environ Microbiol 2009; 11: 1242-1253.

60 El Ahmer OR, Essery SD, Saadi AT, et al. The effect of cigarette smoke on adherence of respiratory pathogens to buccal epithelial cells. FEMS Immunol Med Microbiol 1999; 23: 27-36.

61 Bagaitkar J, Demuth DR, Scott DA. Tobacco use increases susceptibility to bacterial infection. Tob Induc Dis 2008; 4: 12.

62 Palmer RM, Wilson RF, Hasan AS, et al. Mechanisms of action of environmental factors-tobacco smoking. J Clin Periodontol 2005; 32: 180-195.

63 Zambon JJ, Grossi SG, Machtei EE, et al. Cigarette smoking increases the risk for subgingival infection with periodontal pathogens. J Periodontol 1996; 67: 1050-1054.

64 van der Weijden GA, de Slegte C, Timmerman MF, et al. Periodontitis in smokers and non-smokers: intra-oral distribution of pockets. J Clin Periodontol 2001; 28: 955-960.

65 Haffajee AD, Socransky SS. Relationship of cigarette smoking to the subgingival microbiota. J Clin Periodontol 2001; 28: 377-388.

66 Shchipkova AY, Nagaraja HN, Kumar PS. Subgingival microbial profiles of smokers with periodontitis. J Dent Res 2010; 89: 1247-1253.

67 van Winkelhoff AJ, Bosch-Tijhof CJ, Winkel EG, et al. Smoking affects the subgingival microflora in periodontitis. J Periodontol 2001; 72: 666-671.

68 Delima SL, McBride RK, Preshaw PM, et al. Response of subgingival bacteria to smoking cessation. J Clin Microbiol 2010; 48: 2344-2349.

69 Goldstein-Daruech N, Cope EK, Zhao KQ, et al. Tobacco smoke mediated induction of sinonasal microbial biofilms. PLoS One 2011; 6: e15700.

70 Aronson MD, Weiss ST, Ben RL, et al. Association between cigarette smoking and acute respiratory tract illness in young adults. JAMA 1982; 248: 181-183.

71 Greenberg D, Givon-Lavi N, Broides A, et al. The contribution of smoking and exposure to tobacco smoke to Streptococcus pneumoniae and Haemophilus influenzae carriage in children and their mothers. Clin Infect Dis 2006; 42: 897-903.

72 Fischer M, Hedberg K, Cardosi P, et al. Tobacco smoke as a risk factor for meningococcal disease. Pediatr Infect Dis I 1997; 16 979-983.

73 Iles K, Poplawski NK, Couper RT. Passive exposure to tobacco smoke and bacterial meningitis in children.J Paediatr Child Health 2001; 37: 388-391.

74 Jones LL, Hashim A, McKeever T, et al. Parental and household smoking and the increased risk of bronchitis, bronchiolitis and other lower respiratory infections in infancy: systematic review and meta-analysis. Respir Res 2011; 12: 5.

75 Sethi S, Mallia P, Johnston SL. New paradigms in the pathogenesis of chronic obstructive pulmonary disease II. Proc Am Thorac Soc 2009; 6: 532-534. 
76 Sethi S, Evans N, Grant BJ, et al. New strains of bacteria and exacerbations of chronic obstructive pulmonary disease. $\mathrm{N} \mathrm{Engl} \mathrm{J}$ Med 2002; 347: 465-471.

77 Sethi S, Murphy TF. Infection in the pathogenesis and course of chronic obstructive pulmonary disease. N Engl J Med 2008; 359: 2355-2365.

78 Rao VK, Krasan GP, Hendrixson DR, et al. Molecular determinants of the pathogenesis of disease due to non-typable Haemophilus influenzae. FEMS Microbiol Rev 1999; 23: 99-129.

79 Mukundan D, Ecevit Z, Patel M, et al. Pharyngeal colonization dynamics of Haemophilus influenzae and Haemophilus haemolyticus in healthy adult carriers. J Clin Microbiol 2007; 45: 3207-3217.

80 Samuelson A, Freijd A, Jonasson J, et al. Turnover of nonencapsulated Haemophilus influenzae in the nasopharynges of otitis-prone children. J Clin Microbiol 1995; 33: 2027-2031.

81 Margolis E, Yates A, Levin BR. The ecology of nasal colonization of Streptococcus pneumoniae, Haemophilus influenzae and Staphylococcus aureus: the role of competition and interactions with host's immune response. BMC Microbiol 2010; 10: 59.

82 Ratner AJ, Lysenko ES, Paul MN, et al. Synergistic proinflammatory responses induced by polymicrobial colonization of epithelial surfaces. Proc Natl Acad Sci USA 2005; 102: 3429-3434.

83 Lysenko ES, Clarke TB, Shchepetov M, et al. Nod1 signaling overcomes resistance of $S$. pneumoniae to opsonophagocytic killing. PLoS Pathog 2007; 3: e118.

84 Lysenko ES, Ratner AJ, Nelson AL, et al. The role of innate immune responses in the outcome of interspecies competition for colonization of mucosal surfaces. PLoS Pathog 2005; 1: e1.

85 Lysenko ES, Lijek RS, Brown SP, et al. Within-host competition drives selection for the capsule virulence determinant of Streptococcus pneumoniae. Curr Biol 2010; 20: 1222-1226.

86 Regueiro V, Campos MA, Morey P, et al. Lipopolysaccharidebinding protein and CD14 are increased in the bronchoalveolar lavage fluid of smokers. Eur Respir J 2009; 33: 273-281.

87 Morey P, Cano V, Martí-Lliteras P, et al. Evidence for a nonreplicative intracellular stage of nontypable Haemophilus influenzae in epithelial cells. Microbiology 2011; 157: 234-250.

88 King PT, Ngui J, Farmer MW, et al. Cytotoxic T lymphocyte and natural killer cell responses to non-typeable Haemophilus influenzae. Clin Exp Immunol 2008; 152: 542-551.

89 de Bree GJ, Daniels H, Schilfgaarde M, et al. Characterization of $\mathrm{CD} 4+$ memory $\mathrm{T}$ cell responses directed against common respiratory pathogens in peripheral blood and lung. J Infect Dis 2007; 195: 1718-1725.

90 Kadioglu A, Weiser JN, Paton JC, et al. The role of Streptococcus pneumoniae virulence factors in host respiratory colonization and disease. Nat Rev Microbiol 2008; 6: 288-301.

91 Almirall J, Bolibar I, Balanzo X, et al. Risk factors for communityacquired pneumonia in adults: a population-based case-control study. Eur Respir J 1999; 13: 349-355.

92 Almirall J, Gonzalez CA, Balanzo X, et al. Proportion of community-acquired pneumonia cases attributable to tobacco smoking. Chest 1999; 116: 375-379.

93 Nuorti JP, Butler JC, Farley MM, et al. Cigarette smoking and invasive pneumococcal disease. Active Bacterial Core Surveillance Team. N Engl J Med 2000; 342: 681-689.

94 Vander Top EA, Wyatt TA, Gentry-Nielsen MJ. Smoke exposure exacerbates an ethanol-induced defect in mucociliary clearance of Streptococcus pneumoniae. Alcohol Clin Exp Res 2005; 29: 882-887.

95 Phipps JC, Aronoff DM, Curtis JL, et al. Cigarette smoke exposure impairs pulmonary bacterial clearance and alveolar macrophage complement-mediated phagocytosis of Streptococcus pneumoniae. Infect Immun 2010; 78: 1214-1220.

96 Parameswaran GI, Wrona CT, Murphy TF, et al. Moraxella catarrhalis acquisition, airway inflammation and protease-antiprotease balance in chronic obstructive pulmonary disease. $B M C$ Infect Dis 2009; 9: 178.
97 Amedei A, Della Bella C, Niccolai E, et al. Moraxella catarrhalisspecific Th1 cells in BAL fluids of chronic obstructive pulmonary disease patients. Int J Immunopathol Pharmacol 2009; 22: 979-990.

98 Drannik AG, Pouladi MA, Robbins CS, et al. Impact of cigarette smoke on clearance and inflammation after Pseudomonas aeruginosa infection. Am J Respir Crit Care Med 2004; 170: 1164-1171.

99 Cantin AM, Hanrahan JW, Bilodeau G, et al. Cystic fibrosis transmembrane conductance regulator function is suppressed in cigarette smokers. Am J Respir Crit Care Med 2006; 173: 1139-1144.

100 Martínez-Solano L, Macía MD, Fajardo A, et al. Chronic Pseudomonas aeruginosa infection in chronic obstructive pulmonary disease. Clin Infect Dis 2008; 47: 1526-1533.

101 Marston BJ, Lipman HB, Breiman RF. Surveillance for Legionnaires' disease. Risk factors for morbidity and mortality. Arch Intern Med 1994; 154: 2417-2422.

102 Bates MN, Khalakdina A, Pai M, et al. Risk of tuberculosis from exposure to tobacco smoke: a systematic review and metaanalysis. Arch Intern Med 2007; 167: 335-342.

103 Feng Y, Kong Y, Barnes PF, et al. Exposure to cigarette smoke inhibits the pulmonary T-cell response to influenza virus and Mycobacterium tuberculosis. Infect Immun 2011; 79: 229-237.

104 Varma-Basil M, Dwivedi SK, Kumar K, et al. Role of Mycoplasma pneumoniae infection in acute exacerbations of chronic obstructive pulmonary disease. J Med Microbiol 2009; 58: 322-326.

105 Kariya C, Chu HW, Huang J, et al. Mycoplasma pneumoniae infection and environmental tobacco smoke inhibit lung glutathione adaptive responses and increase oxidative stress. Infect Immun 2008; 76: 4455-4462.

106 Barnes PJ. Corticosteroid effects on cell signalling. Eur Respir J 2006; 27: 413-426.

107 Barnes PJ, Stockley RA. COPD: current therapeutic interventions and future approaches. Eur Respir J 2005; 25: 1084-1106.

108 Bellanger AP, Millon L, Khoufache K, et al. Aspergillus fumigatus germ tube growth and not conidia ingestion induces expression of inflammatory mediator genes in the human lung epithelial cell line A549. J Med Microbiol 2009; 58: 174-179.

109 Mogensen TH, Berg RS, Paludan SR, et al. Mechanisms of dexamethasone-mediated inhibition of Toll-like receptor signaling induced by Neisseria meningitidis and Streptococcus pneumoniae. Infect Immun 2008; 76: 189-197.

110 Skornik WA, Dressler DP. The effects of short-term steroid therapy on lung bacterial clearance and survival in rats. Ann Surg 1974; 179: 415-421.

111 Satoh S, Oishi K, Iwagaki A, et al. Dexamethasone impairs pulmonary defence against Pseudomonas aeruginosa through suppressing iNOS gene expression and peroxynitrite production in mice. Clin Exp Immunol 2001; 126: 266-273.

112 Imasato A, Desbois-Mouthon C, Han J, et al. Inhibition of p38 MAPK by glucocorticoids via induction of MAPK phosphatase-1 enhances nontypeable Haemophilus influenzae-induced expression of Toll-like receptor 2. J Biol Chem 2002; 277: 47444-47450.

113 Komatsu K, Jono H, Lim JH, et al. Glucocorticoids inhibit nontypeable Haemophilus influenzae-induced MUC5AC mucin expression via MAPK phosphatase-1-dependent inhibition of p38 MAPK. Biochem Biophys Res Commun 2008; 377: 763-768.

$114 \mathrm{Li}$ JD. Exploitation of host epithelial signaling networks by respiratory bacterial pathogens. J Pharmacol Sci 2003; 91: 1-7.

115 Shuto T, Imasato A, Jono H, et al. Glucocorticoids synergistically enhance nontypeable Haemophilus influenzae-induced Toll-like receptor 2 expression via a negative cross-talk with p38 MAP kinase. J Biol Chem 2002; 277: 17263-17270.

116 Barbier M, Agustí A, Albertí S. Fluticasone propionate reduces bacterial airway epithelial invasion. Eur Respir J 2008; 32: 1283-1288.

117 Ernst P, Gonzalez AV, Brassard P, et al. Inhaled corticosteroid use in chronic obstructive pulmonary disease and the risk of 
hospitalization for pneumonia. Am J Respir Crit Care Med 2007; 176: 162-166.

118 Barnes PJ. Reduced histone deacetylase in COPD: clinical implications. Chest 2006; 129: 151-155.

119 Barnes PJ. ABC of chronic obstructive pulmonary disease. Future treatments. BMJ 2006; 333: 246-248.

120 Barnes PJ. Novel signal transduction modulators for the treatment of airway diseases. Pharmacol Ther 2006; 109: 238-245.

121 Barnes PJ, Hansel TT. Prospects for new drugs for chronic obstructive pulmonary disease. Lancet 2004; 364: 985-996.

122 Barnes PJ. Theophylline in chronic obstructive pulmonary disease: new horizons. Proc Am Thorac Soc 2005; 2: 334-339.

123 Marwick JA, Caramori G, Stevenson CS, et al. Inhibition of PI3K $\delta$ restores glucocorticoid function in smoking-induced airway inflammation in mice. Am J Respir Crit Care Med 2009; 179: 542-548.

124 Coraux C, Kileztky C, Polette M, et al. Airway epithelial integrity is protected by a long-acting $\beta_{2}$-adrenergic receptor agonist. Am J Respir Cell Mol Biol 2004; 30: 605-612.

125 Fragaki K, Kileztky C, Trentesaux C, et al. Downregulation by a long-acting $\beta_{2}$-adrenergic receptor agonist and corticosteroid of Staphylococcus aureus-induced airway epithelial inflammatory mediator production. Am J Physiol Lung Cell Mol Physiol 2006; 291: L11-L18.

126 Dowling RB, Johnson M, Cole PJ, et al. Effect of salmeterol on Haemophilus influenzae infection of respiratory mucosa in vitro. Eur Respir J 1998; 11: 86-90.
127 Maris NA, Florquin S, van't Veer C, et al. Inhalation of $\beta-2$ agonists impairs the clearance of nontypable Haemophilus influenzae from the murine respiratory tract. Respir Res 2006; 7: 57.

128 Lu CC, Lai HC, Hsieh SC, et al. Resveratrol ameliorates Serratia marcescens-induced acute pneumonia in rats. J Leukoc Biol 2008; 83: 1028-1037.

129 Wang WB, Lai HC, Hsueh PR, et al. Inhibition of swarming and virulence factor expression in Proteus mirabilis by resveratrol. J Med Microbiol 2006; 55: 1313-1321.

130 Zaidi SF, Ahmed K, Yamamoto T, et al. Effect of resveratrol on Helicobacter pylori-induced interleukin-8 secretion, reactive oxygen species generation and morphological changes in human gastric epithelial cells. Biol Pharm Bull 2009; 32: 1931-1935.

131 Docherty JJ, Fu MM, Tsai M. Resveratrol selectively inhibits Neisseria gonorrhoeae and Neisseria meningitidis. J Antimicrob Chemother 2001; 47: 243-244.

132 Bishop BL, Duncan MJ, Song J, et al. Cyclic AMP-regulated exocytosis of Escherichia coli from infected bladder epithelial cells. Nat Med 2007; 13: 625-630.

133 Dowling RB, Johnson M, Cole PJ, et al. The effect of rolipram, a type IV phosphodiesterase inhibitor, on Pseudomonas aeruginosa infection of respiratory mucosa. J Pharmacol Exp Ther 1997; 282: 1565-1571.

134 Soares AC, Souza DG, Pinho V, et al. Impaired host defense to Klebsiella pneumoniae infection in mice treated with the PDE4 inhibitor rolipram. Br J Pharmacol 2003; 140: 855-862. 